\title{
CONTINUOUS PERIPHERAL NERVE BLOCKS (CPNB) FOR PAIN MANAGEMENT AND WOUND CARE AT A SURGERY WARD - TWO SUCCESS CLINICAL CASES
}

J. Carreteiro ${ }^{1}$, S. Moreira ${ }^{1}$, R. Silva ${ }^{1}$.

${ }^{1}$ Centro Hospitalar de Lisboa Ocidental, Anaesthesiology, Lisbon, Portugal

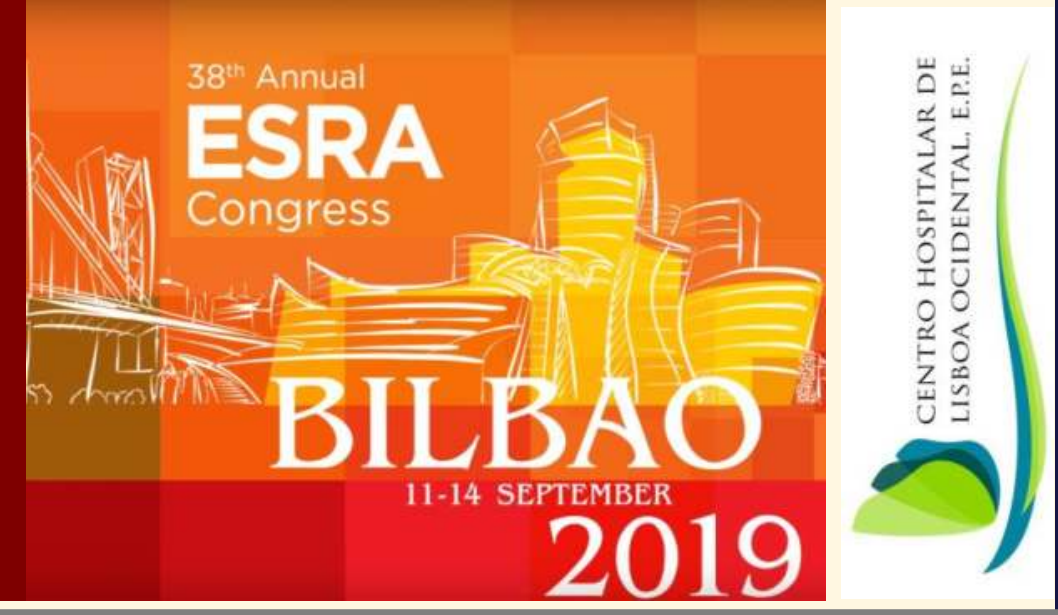

\section{BACKGROUND AND AIMS}

A continuous peripheral nerve block (CPNB) consists of a percutaneously inserted catheter with its tip adjacent to a target nerve/plexus through which local anesthetic may be administered (by infusion or intermittent boluses), providing a prolonged block that may be titrated to the desired effect. It has proven to be a very effective strategy in postoperative pain management.

We present two cases showing their benefits on inpatients on a Surgical Ward.

\section{METHODS AND RESULTS}

\section{CASE A}

Anesthesia assessment due to opioid adverse effects (somnolence and bradypnea) on an 82-year-old female, ASA III, presenting with painful external malleolus ulcer requiring transdermal fentanyl for pain control but with excessive somnolence and bradypnea.

$\rightarrow$ A continuous ultrasound-guided popliteal sciatic block was performed (Figure $\mathbf{1}$ and $\mathbf{2}$ ).

Bolus of ropivacaine $0.2 \% 20 \mathrm{ml}$ was administered through the catheter and a ropivacaine $0.2 \% \quad 4.1 \mathrm{~mL} / \mathrm{h}$ perfusion was maintained over 21 days, with opioid free multimodal analgesia scheme.

RESULTS: VAS score 0 during all the recovery time, with no need of opioid analgesic therapy, nor rescue analgesia.

\section{CASE B}

44-year-old male, ASA I, painful hand cellulitis (Figure 3) previously submitted to surgical cleaning and debridement, requiring daily wound care and opioid based analgesia.

$\rightarrow$ A continuous ultrasound-guided costoclavicular block was performed.

Bolus of ropivacaine $0.375 \% 15 \mathrm{ml}$ was delivered through the catheter and a ropivacaine $0.1 \% \quad 4.1 \mathrm{~mL} / \mathrm{h}$ perfusion was maintained over 16 days for pain management during wound care period.

RESULTS: Patient VAS score $<3$ during daily wound care (Figure 4).

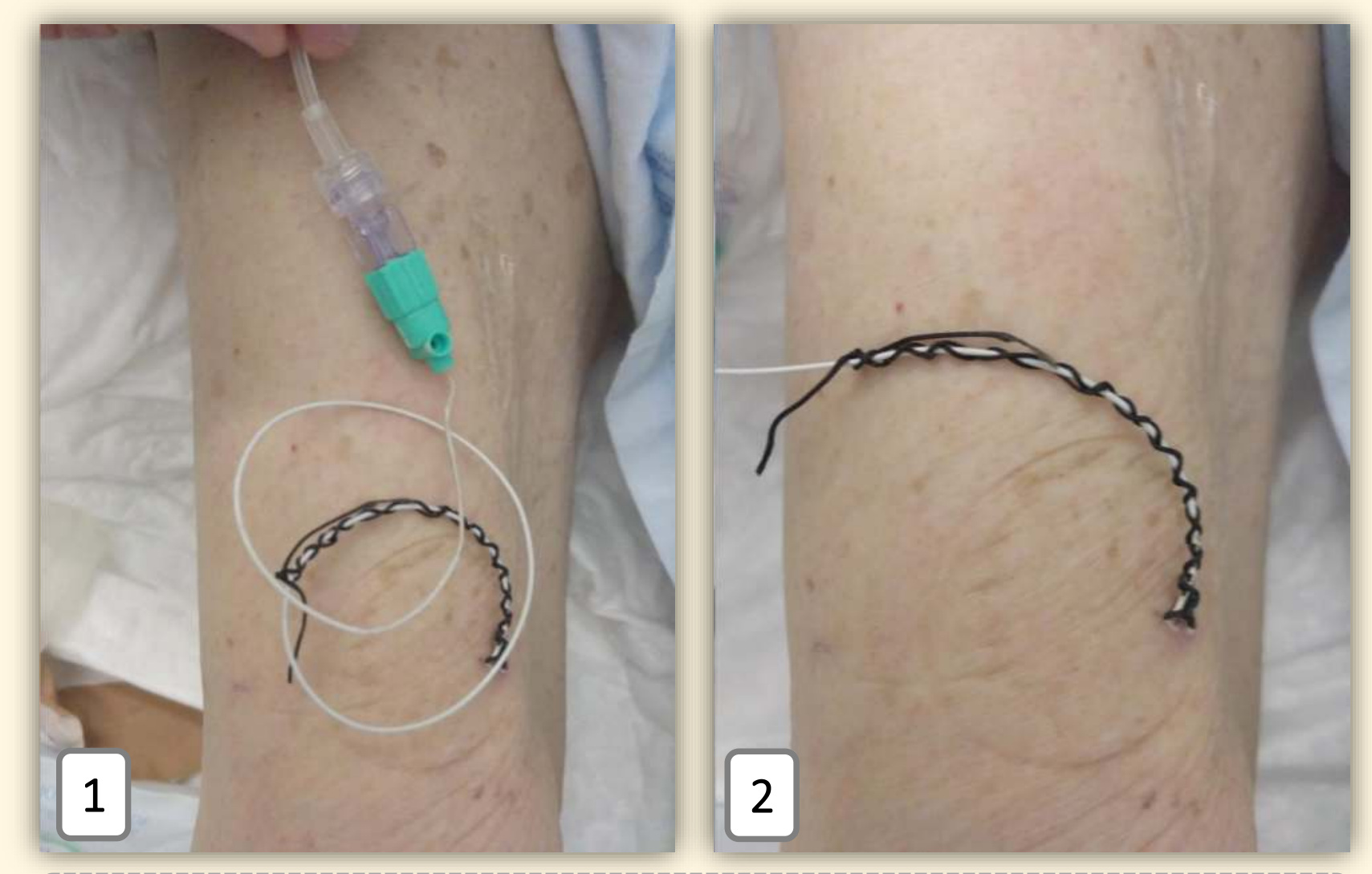

Figure 1 and 2: popliteal-sciatic catheter.

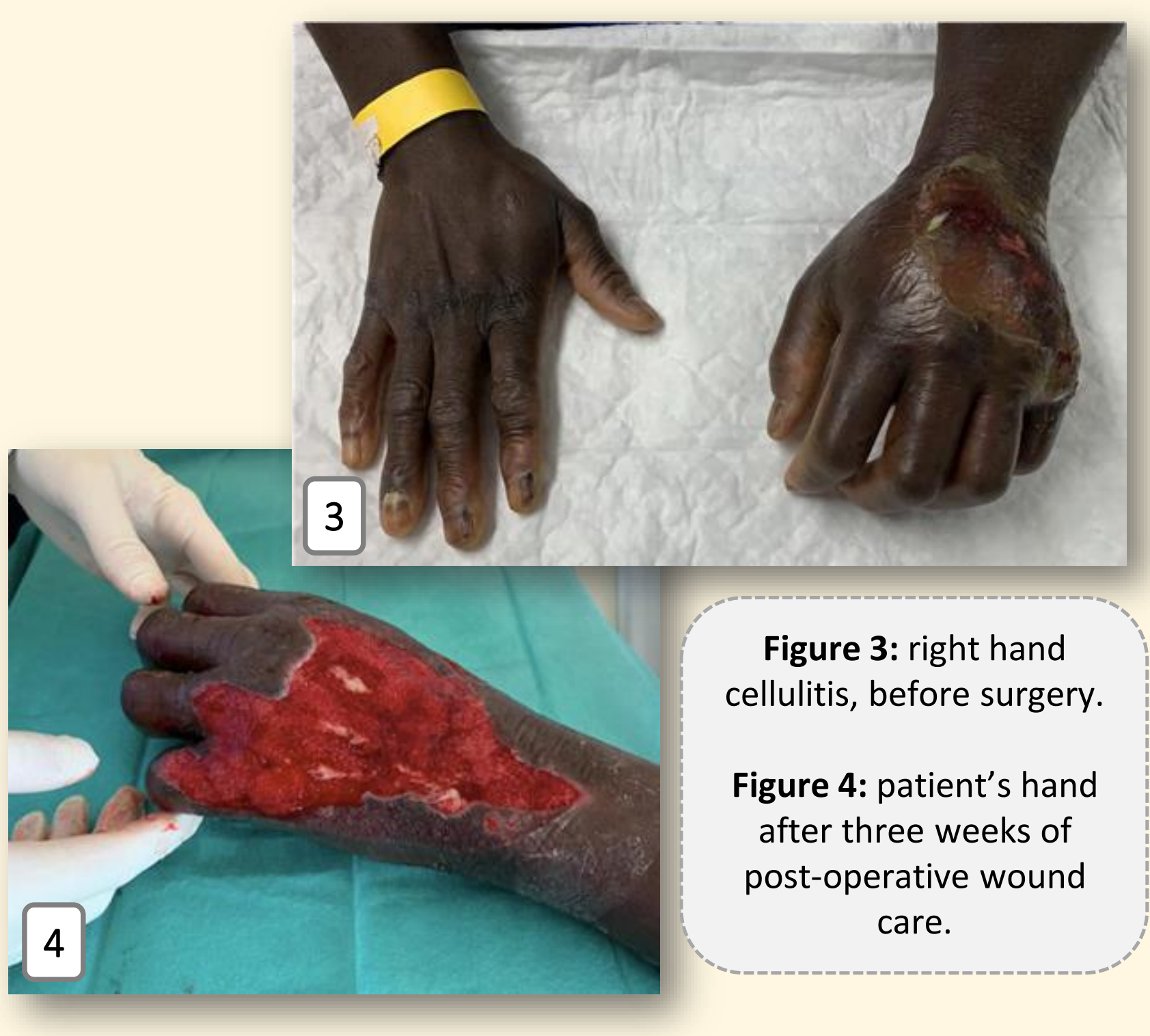

\section{CONCLUSIONS}

CPNB provided a safe and effective approach for pain management. No patient reported signs of neurological injury or any other side effects and there was no signs of infection. In both cases it allowed for wound care, reducing opioid requirements, minimizing adverse effects as well as allowing for early mobilization and efficient rehabilitation. Continuous nerve block represent an important therapeutic tool in managing perioperative pain, especially when combined with a multimodal approach to pain management. 